\title{
Construction, Identification, and Evaluation of Dengue Promotional Campaign Posters in a Language Classroom
}

\author{
Shabbir Ahmed ${ }^{1}$, Afida Mohamad Ali ${ }^{1}$, Shameem Rafik-Galea ${ }^{2}$, Afiza Mohamad Ali ${ }^{3}$ \& Nor Afiah Mohd \\ Zulkefli $^{4}$ \\ ${ }^{1}$ English Language Department, Faculty of Modern Languages and Communication, Universiti Putra Malaysia, \\ Malaysia \\ ${ }^{2}$ Department of English Language \& Communication, Faculty of Social Sciences and Liberal Arts, UCSI \\ University, Malaysia \\ ${ }^{3}$ Kulliyyah of Languages and Management, International Islamic University Malaysia, Malaysia \\ ${ }^{4}$ Department of Community Health, Faculty of Medicine and Health Sciences, Universiti Putra Malaysia, \\ Malaysia \\ Correspondence: Afida Mohamad Ali, English Language Department, Faculty of Modern Languages and \\ Communication, Universiti Putra Malaysia, 43400, UPM Serdang, Selangor Darul Ehsan, Malaysia.
}

Received: October 4, 2018

Accepted: September 26, 2019

Online Published: November 29, 2019

doi:10.5539/ies.v12n12p150

URL: https://doi.org/10.5539/ies.v12n12p150

\begin{abstract}
Health promotional campaign as the practice of encouraging people to improve health has increased over the last decades in response to various health problems. This paper highlights strategies used by students to develop persuasive promotional campaign posters regarding the dengue health problem. Communication and media studies students were involved to show the combined results between the knowledge of health communication and the effective use of media in constructing an effective and persuasive health messages. A total of 56 students from two cohorts, i.e. twenty-five master's students and thirty-one undergraduates were selected. Kurt Lewin's model of action research was used to set the tasks: campaign objectives, information on dengue, themes/slogans to write the posters either by drawing or designing using a computer. The students were divided into groups where each group was monitored to record, check and evaluate their message writing performances. This study uses the Health Message Review Tool for data analysis which is grounded in the theories of Extended Parallel Process Model and Persuasion Hierarchy Effect. The findings revealed that the participants were able to construct, identify and evaluate major multi modal features in the dengue posters and persuasive elements which included: verbal texts, images, colours, graphic designs, metaphors, 1-sided and 2-sided message, firm conclusion and frames with more effective appeals. It was concluded that similar strategies may well be used in producing other campaign materials such as brochures, pamphlets, and billboards. The linguistic and pedagogic implications are also discussed at the end.
\end{abstract}

Keywords: health campaign message, Kurt Lewin's action research model, poster evaluation checklist, persuasive communication

\section{Introduction}

Malaysia and Singapore are both engaged in campaigns on numerous health issues such as HIV, Diabetes, Dengue as well as in other parts of the world (Kahari, 2013; Hong et al., 2013; Rozhan et al., 2006; Poovaneswari, 1993; H. Rosli \& R. Abd. Rahim, 2015; Winch et al., 2002 cited in Avila et al., 2004; Valbuena, 1987; Brookes \& Harvey, 2015; Siddayao, 2012). Campaign messages are normally disseminated through posters in general for promotional purposes. Promotion activities focus on creating awareness towards the disease; build a positive attitude and preventive measures to change the current practices that are found ineffective. This ineffectiveness may be due to too much information, minimal visual attractiveness and difficulty in comprehending the message contents. Davis (1987 cited in Evans et al., 2009) claims that a campaign requires comprehensive and coordinated action on a very broad front, sustained over a long period. Communication campaign is an organised communication activity, directed at a population for a period, to achieve a goal (Atkin \& Rice, 2012). The promotional campaign, on the other hand, is a series of advertisements using various marketing tools that share similar messages and thoughts to 
promote a business or an event. Different media resources like newspapers, billboards, TV commercials and digital space are used in regular promotional campaigns. Health promotion campaigns are pedagogical in function, with campaigners assuming a position of knowledge and authority over others, targeting populations who are perceived to need instruction and information (Lupton, 1995). Health promoters have drawn upon a repertoire of effective strategies to encourage the public to adopt certain behaviours and to raise their awareness of risk, the most common approaches being fear appeals and the simple presentation of facts (Bates, 2014). Successful communication in health promotion comprises the elements of gaining and retaining the audience's attention and ensuring their correct interpretation of the intended message (Arkin, 1992). One of the common ways to do this is via promotional campaign materials like posters. A poster is a single sheet of visual presentation, containing minimal text and large photographs or illustrations, to promote awareness concisely and effectively. It carries the theme of the awareness campaign through a short and easy to memorise slogan (Mindanao Training Resource Center, n. d.). However, Natec (2008) thinks that a poster is a technical and costly presentation. The production of any poster requires expertise in layout, material selection and how to fuse them in a possible best fit design. It is time consuming and needs careful planning. Tiglao and Keyes (1958) stated that campaign posters could be used as a part of the exhibit or display because they exert great visual power. Furthermore, they state that there should be one dominant idea which can be emphasised by implying qualities like boldness, simplicity, dynamism, shock any or all of them.

Dengue posters are mainly outdoor adverts. They are accessible for use, especially in public spaces like hospitals, health centres and schools to create awareness about a product, a service or an event. They are meant to be persuasive and to convince the public. Persuasion strategies can best be explicated by graphic variables, text contents, images, and framing (Kress \& van Leeuwen, 2006). Posters may use promotional strategies such as, use of texts and text with other elements, theory, targeted and without targeted message, one-way and two-way messages and so on (Head et al., 2013).

The health issue chosen for this study was dengue, which can be considered as a deadly disease in Malaysia and hence an explanation of it is provided in this paper. Dengue fever is a vector-borne disease. "Vector-borne diseases are human illnesses caused by parasites, viruses and bacteria that are transmitted by mosquitoes, sandflies, triatomine bugs, black flies, ticks, tsetse flies, mites, snails and lice (World Health Organization, 2017)", and it falls into the category of infectious disease, and predominantly found in tropical and subtropical countries. Subtropical region refers to a hot and humid climate, whereas tropical zone has mild winter controlled by air. However, it has turned out to be an urban area problem for many countries like Malaysia where the fever does not spare anybody whether children or any adult of any age. Dengue virus is transmitted by female mosquitoes mainly of the species Aedes Aegypti and, to a lesser extent, Aedes Albopictus. This mosquito also transmits Chikungunya, yellow fever and Zika infection. Dengue is widespread throughout the tropics, with local variations in risk influenced by rainfall, temperature and unplanned rapid urbanisation. Severe dengue also known as Dengue Hemorrhagic Fever was first recognised in the 1950s during dengue epidemics in the Philippines and Thailand.

A review on message design in health communication research begins with health campaign message designing scholar, O'Keefe (2006) who suggests that evidence-based message strategy (narrative or statistical approach) for health interventions is more effective for attitude and behaviour change. Nabi (2003) claimed that a message instead of eliciting discrete emotions e.g. fear or guilt or humour, may stimulate multiple emotions such as fear and guilt and humour during the emotional flow. Yzer et al. (2015) believe that the perceived effectiveness (PE) of a message should be measured before using it for a campaign and they proposed suggestions for PE theory and measurement. Sutton et al. (2014) identified that the sources, topics and stylistic features of public health i.e. emergency warning Twitter messages should be re-tweeted. Frank et al. (2015) investigated narrative messages to promote HPV awareness and cervical cancer prevention and reported complex patterns of effects for identification and personal relevance providing crucial direction for future narrative messages. Noar (2006) investigated the role of theory in developing indoor tanning prevention messages via a new scale of measurement and provide suggestions for theoretical adjustments. Zhao and Peterson (2017) examined the influence of psychological and habitual individual disparities on responses to cigarette package warning label messages that emphasized either short or long-term effects of smoking. The study results suggest that the predicted interactions are influenced by message recipient's status: smoker or non-smoker. Savage et al. (2015) explores oral health behaviours in three studies in Appalachia Kentucky and report that they are problematic for which they provide recommendations for message design. Vanderpool et al. (2013) conducted a translational case study on effective HPV vaccination intervention and managed to make them available to three other communities. The study outputs came in the forms of three key health communication intervention design considerations. However, little is known on dengue poster message writing and evaluation using an action research design. 
The primary objective of this study was to examine the possibility of the combined results between the knowledge of health communication and the use of media in producing effective, compelling and persuasive dengue campaign posters to instill awareness and persuade the target participants. Persuasive posters are intentionally designed using an action research design to change health-related attitudes, beliefs and behaviours and the effect of the message to the target audience are considered to be more permanent than that of any other means. Hence, this paper presents the following research questions:

a) How was the dengue campaign posters constructed, identified and evaluated with suggestive feedback for further improvement by the students?

b) How persuasive were the dengue campaign posters produced by the students?

\subsection{Statement of Hypothesis:}

The following null hypothesis was applied to the research question (see research question ' $b$ ') mentioned above.

$H_{o}$ : There is no significant difference between the mean scores of six dengue campaign posters.

\section{Method}

\subsection{Research Design}

This study employed an action research design for setting the classroom tasks to see how students of communication and media studies can produce effective and persuasive health campaign messages under the paradigms of both qualitative and quantitative research. Bradbury and Reason (2006) stress that "action research is about working towards practical outcomes and also about creating new forms of understanding, since action research without understanding is blind, just as theory without action is meaningless." The study design used Kurt Lewin's action research model whereby the posters were constructed, identified, evaluated and improved through successive sessions. The rationale for using action research is to create opportunities for the practice of health message writing in a classroom setting based on a specific health problem, i.e. dengue. The classroom practice was used to allow the researcher to find the linguistic conventions that arise in the process. Thus, the identified conventions could then be addressed in the following class to improve the quality and efficacy of producing dengue posters. These health campaign messages took the form of posters which were then evaluated at the end of the students' presentation in two language classrooms: Corporate Communication and Media Studies. Two separate types of posters were practiced in the class, namely hand drawn, and computer-designed posters. The language classrooms were selected for two reasons, the first was to pave the way for using relevant theories and practical knowledge in the design of persuasive posters and ensuring students' active participation in actual campaigns later. The second reason was to enable the researchers to better understand the process of effective and persuasive campaign message writing.

\subsection{Participants}

A sample size of 56 students, i.e. twenty-five from a master's class of Corporate Communication and thirty-one from an undergraduate class of Media Study were invited to two knowledge sharing sessions on writing campaign messages. They were selected using purposive sampling with the majority of the participants being between the age of 22 and 24 years. They have been learning English for a period of 16 to 20 years. Only a few have English as their mother tongue. The rest speaks Malay as their first language. The two groups: students of Communication and Media Studies were chosen based on their background knowledge on relevant theories of communication and media which they have learned through coursework and personal exposures to various health promotional campaigns e.g. "Dengue now and then". According to Popesku and Verman (2000), one of the key aspects of health promotion is the "creation and dissemination of clear, effective and relevant public health messages" (p. 24). Similarly, Lasswell's (1948 cited in Shoemaker \& Reese, 1996) paradigm of communication explains that message producers convey a vital message to their target audience using mass or popular media to persuade them (p. 12). In this study, students act as message producers where they were instructed to use any possible means to design the posters i.e. hand-drawn or computer technology.

\subsection{The Data}

The qualitative data comprised of dengue campaign posters produced by the students during the knowledge-sharing sessions in the classroom. Firstly, following Atkin and Rice (2012) public communication campaigns, the message producers, in this case, the students, were informed about the problem i.e. dengue as an acute health problem. Secondly, the target audience was determined with specific demographic details. For instance, the intended audience should be in the range of 9 to11 years old and of Malaysian citizenship, able read and understand posters written in either Malay or in English and must not be colour-blind. Next, the general, 
specific and communicative objectives were explained to the students to make way for theme selection. Once these have been established, students began designing their posters in groups of four to five pupils. The outcome of this activity generated ten hand-drawn posters in the first session and in the second session, seven hand-written and three computer-designed posters were produced. The rationale was to encourage them to design the posters in the way that they are comfortable with and that might motivate them.

As for the quantitative data, evaluative responses from the students were collected using 12-point Health Message Review Tool (Public Health Ontario, 2012).

\subsection{Data Collection Tools}

A 12-point Health Message Review Tool (Public Health Ontario, 2012) with a recommendation for further improvement section (for both hand-drawn and computer designed posters) is used for collecting the data. The twelve points refer to aspects such as message clarity in which the strongest point is given at the beginning with good evidence for threats and benefits, believability, appropriate tone, appeal, not harmful or offensive to the audience, displayed identity throughout and, expected to get and maintain the attention of the audience (see Appendix A).

Persuasive health campaign messages are constructed as part of a health communication campaign and they may fail or succeed. This Health Message Review Tool serves as criteria for developing persuasive health message by helping message producers in deciding three main components of any health message: sharing most important information (The What), reasons or benefits of acting (The So What) and stating the necessary action (The Now What). The tool may also be used to assess health campaign messages. The tool is grounded in McGuire's (1981) Hierarchy of Effect theory, which describes the steps of behaviour change by an audience. To understand the persuasion process of the posters with a view to better understand the persuasive strategies employed by the students, a health message review tool was adopted and adapted using McGuire's (2001) Persuasion theory for poster evaluation. In the development of the review tool, McGuire's model emerged as a suitable conceptual framework to use for this purpose because it is practical. It also allowed the breakdown of the evaluation process into twelve discrete steps that permitted this assessment. Besides, Witte's (1998 cited in Jansen, 2003) Extended Parallel Process Model (EPPM) along with Persuasion Theory of McGuire explains how and why different types of appeals for action may or may not work. The EPPM, is a popularly used model in health communication campaigns which looks at how a message can persuade an intended audience to adopt a healthy behavior. This model involves fear appeals through arousal, perceived susceptibility and vulnerability, awareness of the likelihood of a hazard, framing of messages in terms of potential gains or losses, and perceived threat which can be effective in changing risky attitudes and behaviors (Stephenson \& Witte, 2001). However, two, parallel, responses to fear may occur: a cognitive process involving ways to control or avert a danger, which may take advantage of the health message using a fear appeal, and an emotional process that attempts to control the fear, often by denial or coping, which will generally reject the message due to the fear appeal. According to the EPPM, the fear appeal entails both perceived threat and perceived efficacy. Perceived threat influences the strength of a danger or fear control response. In other words, when a person faces a health risk, he can manage the risk accordingly. However, perceived efficacy enables one's ability to execute actions to reduce the danger or fear. So, a fear appeal must successfully convey both that the threat is salient and significant, and that the audience member can do something about it, and probably by emphasizing efficacy before threat. The third possible response is to ignore the message if it is deemed irrelevant or insignificant to the respondents.

\subsection{Data Analysis Procedure}

Data were analysed qualitatively i.e. using descriptive analysis on the poster construction conventions and strategies i.e. audience factors, message factors, firm conclusion, 1-sided versus 2-sided messages, rhetorical devices (repetition, argument, statistics, humour and so on), verbal and visual features (Kress \& van Leeuwen, 2006), anchorage (relationship), use of graphic design, popular cartoon characters, fear appeal, providing statistics or examples, theme or slogan, source factors, use of logistics, drawn from past literature and relevant studies on health campaign messaging. For quantitative data, a one-way ANOVA test was used to analyse the respondents' responses on dengue posters. The qualitative analysis followed an inductive process which involved several concepts adapted from Morrison et al. (2005) and the Health Message Review Tool (2012). In phase one, the concepts in the posters were examined (Table 1). Phase two looked at inherent relationships between posters' elements to demonstrate how the concepts are logically connected (see Table 2 and 3). The third phase of data analysis focused on the evaluation responses made by the students on the hand-drawn or computer-generated posters. This final phase involves the collection of students' evaluative responses to the posters, where students, both individually and as groups, grade each poster using a Likert scale in the Health Message Review Tool. The 
mean score with a standard deviation is calculated for each poster. The overall process of data analysis involved the following steps: first, participants' informed consents were obtained in order to be part of the study. Then, respondents were allowed to use any means they preferred i.e. coloured pens, markers, glues, scissors, poster papers and computer applications in producing the posters. The completed posters were shown to the class for peer evaluation and constructive feedback was gathered. All posters were critically assessed on their merits and demerits with suggestive remarks.

\subsection{Conducting the Sessions}

A summary of the poster writing session is presented here for the readers to understand how the class was conducted and what outcomes were achieved after the session was over. In effect, two separate sessions were taken to mark the overall progress in message writing, identifying and evaluating dengue campaign posters.

\subsection{Planning the Sessions}

It was essential for the researchers to plan the sessions well to attain the expected outcomes from the instructional endeavours. The plan was to make the encounters as interactive as possible. This included creating lesson plans for both sessions with the following teaching objectives such as: introduce the relevant theory or previous appeals used in dengue posters, instruct the students to produce and present new dengue campaign posters, provide linguistic inputs that contribute to designing effective and persuasive campaign posters. These plans are aimed at obtaining the set learning outcomes i.e. constructing, identifying and evaluating posters. Next, classroom activities were determined. For each activity, a learning objective and outcome were set to achieve by the end of the session (see Appendix B). Some essential teaching aids such as PowerPoint presentations, relevant video clips on dengue promotional campaigns and sample posters were used to inform the participants. Lewin's Model of Action Research (see Figure 1) was used to set the task in this study since it was found to be a useful model with distinct steps. Its speciality is its reconnaissance stage. At this stage, the action researcher can collect all the information, take notes, study to bring new ideas and improve the lesson plan. Reconnaissance stage can be undertaken before a plan is created and it could also include gathering information about a similar session or other data, further reading of pertinent literature, and discussing with colleagues and peers. Figure 1 displays the action research model of Kurt Lewin which was cited by Smith (2001).

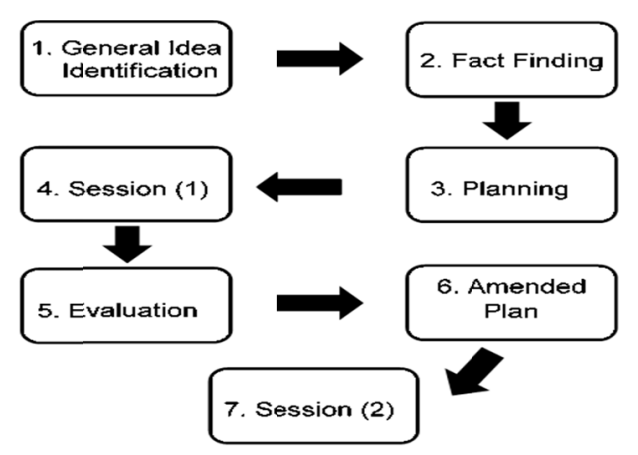

Figure 1. Kurt Lewin's model of action research (Smith, 2001)

Based on Figure 1, the research team identified the general theme i.e. campaign message writing. To understand all the terms and concepts of campaign message writing, literature on past and recent studies, and guidelines on health campaign message development (writing, identifying, evaluating) were carried out on dengue promotional campaign

First, a $1 \frac{1}{2}$ hour session with the students was conducted which involved a number of activities as follows: checking their present level of knowledge on the topic and giving some basic ideas (Laswell, 1948), selecting a theme or slogan, obtaining all required information about the target audience, setting general and specific campaign objectives, selecting appropriate media or medium for communication, confirming a campaign date, assessing a tentative budget for poster making and finalizing strategies for campaign material writing process. For instance, focus questions like: Have you seen any poster? What did the poster look like? Why was the poster written? Who wrote the poster? What benefits could you get from it? These questions were used to brainstorm and refresh their schema i.e. background knowledge.

At the end of the session 1, the students were instructed to evaluate posters using the four-point Likert scale i.e. 
great, good, fair, and fail. To this end the "Health Message Review Tool (Public Health Ontario, 2012)" was used to assess the posters. By using this tool, participants were more aware of key information regarding campaign message writing, which enhances their knowledge of effective campaign message writing strategies. For instance, knowing the audience, informational needs, relevant theories, benefits and incentives for the message to process, understand and act upon.

In some instances, the dissemination of information was improved to make the session more enjoyable and productive. For example, instructor's power-point slides were readjusted with new contents, students could use computer or smartphones to write and design more effective and persuasive posters, as an alternative to hand-drawn posters.

A second session of repeating the class was carried out to understand the level of improvement that the participants can demonstrate in constructing, identifying and evaluating the posters after adjusting previously used lesson plans and teaching materials. A week time was allocated for the second session (back to back). This duration was used for reflecting on the gaps of the first session, e.g. adding more ideas in upgrading teaching materials, allowing them to design posters using computers, and mobiles.

The development of dengue campaign posters entailed the following steps: Participatory students were shown past dengue posters to know how they were made. Then students were invited to write new posters according to the lesson plan. Each group identified the essential contents for poster construction in front of the class. Out of ten posters on dengue campaign, the students managed to evaluate six posters along with recommendations.

\subsection{Writing and Identifying Essential Factors in Dengue Campaign Posters}

This action research succeeds in producing twenty posters in two sessions: ten hand-drawn posters in the first class and seven hand-drawn and three computer-generated posters with graphic variables in the second session. The students as dengue poster producers were free to select one or more than one theme and objective for constructing a single poster. Students elected between two topics for designing poster in the first session. Some students picked up "stop corruption" (not a health-related theme selected by mistake which was criticised in the feedback) while other groups opted for "stop dengue" for practicing writing posters. They kept the demographic information of the target audience and their information needs in mind while developing them.

\subsubsection{Evaluation with Recommendations for Further Improvement of the Posters}

At the end of the poster presentation, the students were invited to grade the posters by using the Health Message Review Tool (Public Health Ontario, 2012). The tool which was explained to them contained twelve components to evaluate the persuasiveness of the posters. Explanations were provided for cases where items marked were not clearly understood. The process of evaluation entailed each group of four to five members to grade 6 dengue posters by assigning any of the four scales: great, good, fair and fail. To know i) if all posters were statistically significantly different between groups and within the groups and ii) which poster is the most persuasive and which one is the least persuasive among all six dengue campaign posters, a two-way ANOVA was run using statistical package SPSS version 23. According to Coffman (2003), communication assessment exercise requires one to be consistent with campaign developments (p. 1). This is one of the reasons why strategic communication may be effective in attaining the campaign goals. One way to ensure that health campaigns are successful is to evaluate campaign messages before the actual campaign takes place.

\subsection{Validity and Reliability}

Informed consents were obtained regarding participants' inclusion in this study. They were assured of maintaining the utmost confidentiality of not revealing their identity. Also, respondents were told that participation in this study was voluntary i.e. they might withdraw any time if they wished and the findings of the results would only be used for academic purposes. The data analysed for this study showed consistency, although a small number of participants took part in it. Both quantitative and qualitative data analysis also contributed to enhancing the reliability of the study.

\section{Results}

This section presents the outcomes of the study obtained from the analysis of data. A total of 56 students participated in constructing and evaluating selected dengue campaign posters for the study. However, only 37 respondents completed the posters' evaluation for statistical analysis. Reasons for not obtaining evaluation forms of all 56 students are incomplete evaluation forms and absenteeism to the class. Participants graded the appropriate columns corresponding to the twelve items with assigned scores ranging from 0 to 4 i.e. (4 Fail) and ( 0 Great). In other words, the poster with the lowest mean score was the most persuasive and vice versa. The qualitative findings are presented first in table 1 followed by the quantitative results in Table 2. 


\subsection{Qualitative Findings}

Qualitative findings include key elements of hand-drawn and computer-generated dengue campaign posters followed by students' use of communication and persuasion strategies in constructing dengue posters after identification.

\subsubsection{Key Elements of Hand-Drawn Dengue Campaign Posters}

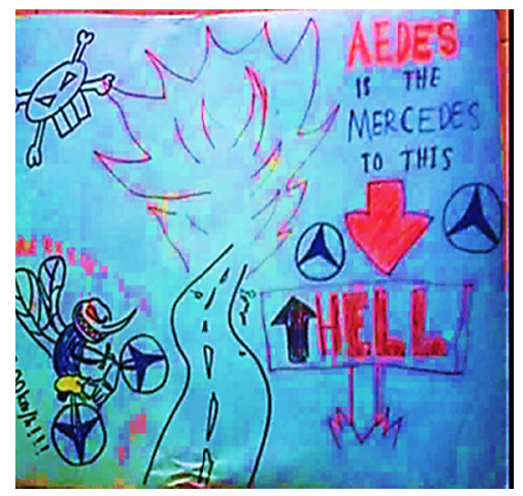

Figure 2. Hand-drawn poster 1 using a metaphor: AEDES IS THE MERCEDES TO THIS HELL

Table 1. Concepts in dengue campaign posters (Morrison et al., 2005)

\begin{tabular}{l} 
A message recipient's new knowledge on the health issue \\
Threats to the health issue in hand \\
Actions suggested reducing the threat \\
Slogan of the campaign message \\
Benefits to be achieved out of the actions being performed \\
Displaying identity throughout the message production \\
\hline
\end{tabular}

Table 1 shows the concepts that can be identified in the students' dengue campaign posters.

An example poster message demonstrating most, or all of the concepts are given here (from Figure 4):

There are 5 types of dengue viruses.

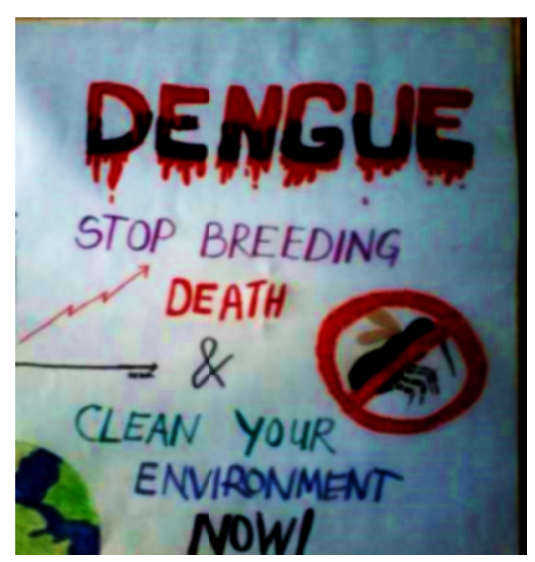

Figure 3. Hand-drawn poster 2 


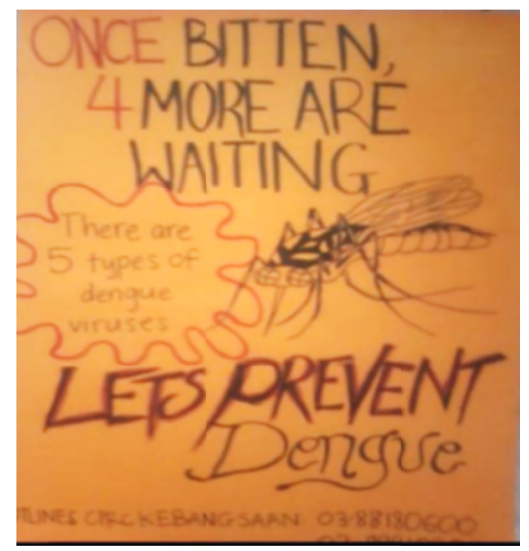

Figure 4. Hand-drawn poster 3

The message in Figure 4 shows the following 'elements as concepts' described in Table 2 below.

Table 2. Concepts and example texts used in health campaign message

\begin{tabular}{lll}
\hline No. & Element as concept & Example text \\
\hline 1 & Recipient (R) & Let's (us) invitation \\
2 & New knowledge (K) & 5 types of dengue viruses \\
3 & Threat (T) & dengue viruses \\
4 & Action (A) & PREVENT (from biting) \\
5 & Displaying identity (I) & HOTLINES CRPC KEBANGSAAN: 03-88180600, 03-88810200 \\
\hline
\end{tabular}

Table 2 illustrates the concepts in a dengue poster text (Figure 4). For instance, the recipient is us-we. The threat is the dengue virus. Each sentence in a dengue message has keywords. The keywords are categorised before the relationship is determined between two concepts within that sentence. All the sentences of the message are considered in this categorisation process. Thus, patterns of the concepts between elements are identified and recorded. Finally, the overall patterns are presented in tabular form.

Table 3. The relationship shown between the elements in dengue campaign messages

\begin{tabular}{ccll}
\hline No. & $\begin{array}{c}\text { Concepts in } \\
\text { pair }\end{array}$ & Relationship & Example text \\
\hline 1 & RK & Recipient receives new knowledge & There are 5 types of dengue viruses \\
2 & RT & Recipient is exposed to threat & ONCE BITTEN 4 MORE ARE WAITING \\
3 & RA & Recipient is invited to take action & LET'S PREVENT \\
4 & RI & Recipient is reminded about the message producer's & HOTLINES CRPC KEBANGSAAN: 03-88180600, \\
& & $03-88810200$ & \\
\hline
\end{tabular}

Table 3 explains the existing relationships between concept pairs of dengue campaign posters. For example, the relationship between the concept pair RA is that the recipient is invited to take action. RI on the other hand shows that the recipient is reminded about the message producer's identity.

\subsubsection{Key Elements of Computer-generated Dengue Campaign Posters}

The same process (e.g. word pattern, concepts, and relationships between concept pairs) is followed in identifying the key elements of computer-generated dengue campaign posters. To avoid being redundant, the results of these key elements are presented here based on Figure 6, a computer-generated poster. Table 4 shows the concepts. Table 5 and 6 show the concepts and the relationships between concept pairs accordingly. 
Table 4. Concepts (in bold letters) identified in computer-generated dengue campaign poster 3 (Figure 6)

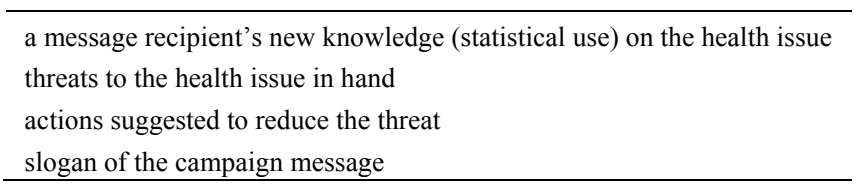

Table 5. Concepts and example texts used in health campaign message

\begin{tabular}{lll}
\hline No. & Element as concept & Example text \\
\hline 1 & Recipient (R) & Let's (us) invitation \\
2 & New knowledge (K) & They've taken 336 of our men \\
3 & Threat (T) & They [Aedes mosquito-shown in the image of a transformer] \\
4 & Action (A) & KILL \\
5 & Slogan (S) & KILL OR BE KILLED \\
\hline
\end{tabular}

Table 6. The relationship shown between the elements in dengue campaign messages

\begin{tabular}{llll}
\hline No. & Concepts in pair & Relationship & Example text \\
\hline 1 & RK & Recipient receives new knowledge & They've taken 336 of our men Humanity is losing! \\
2 & RT & Recipient is exposed to threat & [Target people] BE KILLED \\
3 & RA & Recipient is invited to take action & KILL \\
\hline
\end{tabular}

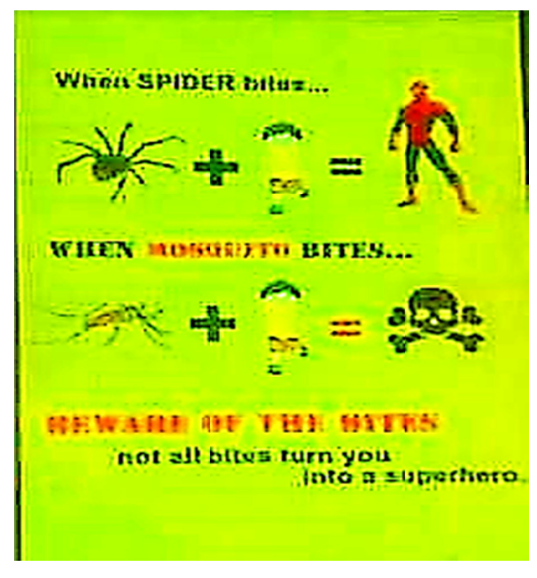

Figure 5. Computer designed poster 1

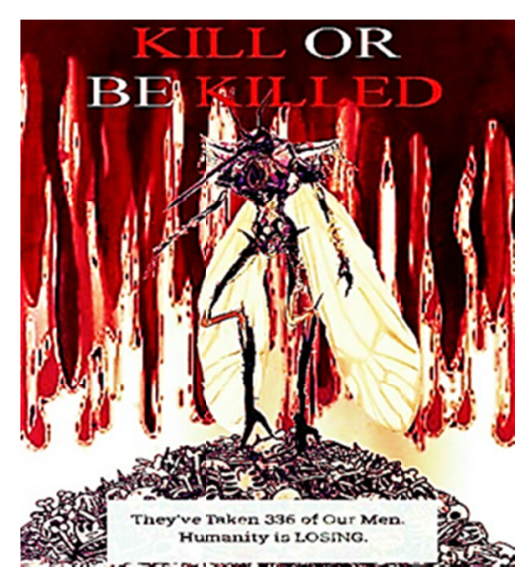

Figure 6. Computer designed poster 2 


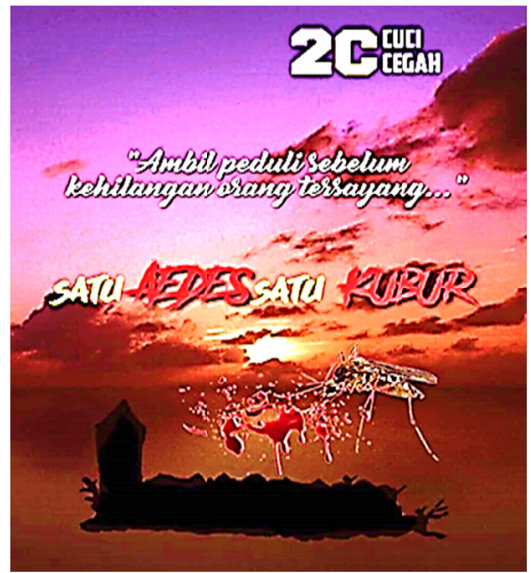

Figure 7. Computer designed poster 3

\subsubsection{Respondents' Use of Communication and Persuasion Strategies}

Results from the poster analysis revealed that students have used various communication and persuasion strategies to construct dengue campaign posters for their target audience. They have kept the audience and message factors in mind and used popular cartoon characters to draw the attention of the target audience. Theories were also considered to guide the visual and verbal text to make them persuasive. They also have used fear appeal, metaphoric expression, statistics, examples, one-sided and two-sided arguments, certain mood or tone to send the messages to their receivers. The inclusion of theme or slogan is used quite uniquely to design posters and influence the target audience to draw a firm conclusion. Graphic variables nonetheless were used in designing the posters for persuasive effect. These elements of the findings are summarised in Table 7 below.

Table 7. Students' use of communication and persuasion strategies in constructing dengue posters

\begin{tabular}{|c|c|c|c|c|}
\hline No. & $\begin{array}{l}\text { Persuasion } \\
\text { strategies }\end{array}$ & Meaning of each item & Identification clues from the poster(s) & Example \\
\hline 1 & Audience Factor & Children of age 9-11 & Posters using cartoon characters & $\begin{array}{l}\text { Figure } 5 \text { and } 6 \text { of } \\
\text { computer-generated posters }\end{array}$ \\
\hline 2 & Message Factor & $\begin{array}{l}\text { Theory, inform or persuade via verbal } \\
\text { and visual texts, new health } \\
\text { information, recommended behaviour } \\
\text { and so on }\end{array}$ & $\begin{array}{l}\text { Extended Parallel Process Model and } \\
\text { Persuasion Theory, there are five types } \\
\text { of dengue viruses, and clean your } \\
\text { environment now }\end{array}$ & $\begin{array}{l}\text { Figure } 4 \text { of hand-drawn poster } \\
3 \text { and Figure } 3 \text { of drawn poster } \\
2\end{array}$ \\
\hline 3 & $\begin{array}{l}\text { Use of Popular } \\
\text { Cartoon } \\
\text { Characters }\end{array}$ & Children of age 9-11 & Posters using cartoon characters & $\begin{array}{l}\text { Figure } 5 \text { and } 6 \text { of } \\
\text { computer-generated posters }\end{array}$ \\
\hline 4 & $\begin{array}{l}\text { Use of Fear } \\
\text { Appeal }\end{array}$ & $\begin{array}{l}\text { Theory, inform or persuade via verbal } \\
\text { and visual texts, new health } \\
\text { information, recommended behaviour } \\
\text { and so on }\end{array}$ & $\begin{array}{l}\text { Extended parallel process model and } \\
\text { persuasion theory, there are five type of } \\
\text { dengue viruses, and clean your } \\
\text { environment now }\end{array}$ & $\begin{array}{l}\text { Figure } 4 \text { of hand-drawn poster } \\
3 \text { and Figure } 3 \text { of drawn } \\
\text { poster } 2\end{array}$ \\
\hline 5 & $\begin{array}{l}\text { Use of Graphic } \\
\text { Design }\end{array}$ & Images to improve communication & $\begin{array}{l}\text { Images of dengue, graph, grave, } \\
\text { Spiderman, and so on. }\end{array}$ & $\begin{array}{l}\text { Figure } 5,6 \text { and } 7 \text {, of computer } \\
\text {-designed posters }\end{array}$ \\
\hline 6 & $\begin{array}{l}\text { Providing } \\
\text { Statistics } \\
\text { Examples }\end{array}$ & $\begin{array}{l}\text { The message may explicitly tell an } \\
\text { audience to draw a conclusion. }\end{array}$ & "not all bites turn you into a superhero". & $\begin{array}{l}\text { Figure } 5 \text { computer-generated } \\
\text { poster } 1\end{array}$ \\
\hline 7 & $\begin{array}{l}\text { 1-Sided Versus } \\
\text { 2-Sided } \\
\text { Messages }\end{array}$ & $\begin{array}{l}\text { A single perspective only favouring } \\
\text { the communicator's point of view. } \\
\text { Presents two opposing sides of the } \\
\text { disease. }\end{array}$ & $\begin{array}{l}\text { "Let's prevent dengue" } \\
\text { When spider bites, you become } \\
\text { Spiderman. But not all bites turn you } \\
\text { into a superhero. }\end{array}$ & $\begin{array}{l}\text { Figure } 4 \text { of hand-drawn poster } \\
3 \\
\text { Figure } \quad 5 \quad \text { of } \\
\text { computer-generated poster } 1\end{array}$ \\
\hline
\end{tabular}




\begin{tabular}{|c|c|c|c|c|}
\hline 8 & $\begin{array}{l}\text { Inclusion of a } \\
\text { Theme or } \\
\text { Slogan }\end{array}$ & Images to improve communication & $\begin{array}{l}\text { Images of dengue, graph, grave, } \\
\text { Spiderman, and so on. }\end{array}$ & $\begin{array}{l}\text { Figure } 5,6 \text { and } 7, \text { of } \\
\text { computer-designed posters }\end{array}$ \\
\hline 9 & $\begin{array}{l}\text { Mood or Tone } \\
\text { of the Message }\end{array}$ & $\begin{array}{l}\text { Imperative statement or } \\
\text { Optative statement }\end{array}$ & $\begin{array}{l}\text { Clean your environment now or Let's } \\
\text { prevent dengue }\end{array}$ & $\begin{array}{l}\text { Figure } 3 \& 4 \text { of hand-drawn } \\
\text { poster } 2 \text { and } 3\end{array}$ \\
\hline 10 & $\begin{array}{l}\text { Use } \\
\text { Metaphor }\end{array}$ & $\begin{array}{l}\text { A direct comparison between two } \\
\text { things: one becomes the other }\end{array}$ & $\begin{array}{l}\text { AEDES IS THE MERCEDES TO } \\
\text { THIS HELL }\end{array}$ & $\begin{array}{l}\text { Figure } 2 \text { of hand-drawn poster } \\
1\end{array}$ \\
\hline 11 & $\begin{array}{l}\text { Firm } \\
\text { Conclusion }\end{array}$ & $\begin{array}{l}\text { The message may explicitly tell an } \\
\text { audience to draw a conclusion. }\end{array}$ & "not all bites turn you into a superhero". & $\begin{array}{l}\text { Figure } 5 \text { computer-generated } \\
\text { poster } 1\end{array}$ \\
\hline
\end{tabular}

\subsubsection{Student's Recommendations for Improving the Posters}

In the study, the students evaluated the posters and provided recommendations for further improvements in various aspects of poster making. Weaknesses were detected in verbal and visual languages, language placement, use of images, and the colour scheme for both of the text forms, background, text font and size. Kress and van Leeuwen's (2006) frame was used to improve language placement. Students were taught to use the top, bottom and centre position more logically and to make the connection between the verbal and visual items more balanced so that meanings can be logically constructed in richer and fuller extent. Some participants mentioned that some posters used more words than necessary. The size and number of the pictures about the hand-made and computer-generated posters (see Figure 2 and 5) were also criticised for improvement. Also, some participants commented that colour combination may well be revised and logically used. One key shortcoming, however, was the use of improper background. Most of the participants suggested using contrasting colours as a better option for reader-friendly texts. Text colour, font and size of the font were deemed crucial for reading the posters to grasp the intended meanings. Hence, the logical combination of small and large fonts was suggested which ensures better viewing leading to better understanding of the information. A summary of linguistic weaknesses, their type and ways to improve them are reported in the following section.

\subsection{Quantitative Findings}

The quantitative findings addressing research question no. 2 entails descriptive and inferential statistical information. Here we begin with descriptive information first (see Table 8).

Table 8. Mean analysis of six dengue posters using 12 items health message review tool

\begin{tabular}{|c|c|c|c|c|c|c|c|c|}
\hline & \multirow{2}{*}{$\mathrm{N}$} & \multirow{2}{*}{ Mean } & \multirow{2}{*}{ Std. Deviation } & \multirow{2}{*}{ Std. Error } & \multicolumn{2}{|c|}{ 95\% Confidence Interval for Mean } & \multirow{2}{*}{ Minimum } & \multirow{2}{*}{ Maximum } \\
\hline & & & & & Lower Bound & Upper Bound & & \\
\hline 1 & 37 & 13.08 & 3.311 & .544 & 11.98 & 14.19 & 6 & 19 \\
\hline 2 & 37 & 13.65 & 3.442 & .566 & 12.50 & 14.80 & 6 & 20 \\
\hline 3 & 37 & 13.16 & 3.693 & .607 & 11.93 & 14.39 & 6 & 19 \\
\hline 4 & 37 & 14.22 & 3.417 & .562 & 13.08 & 15.36 & 6 & 22 \\
\hline 5 & 37 & 14.76 & 3.890 & .640 & 13.46 & 16.05 & 8 & 23 \\
\hline 6 & 37 & 14.38 & 3.459 & .569 & 13.23 & 15.53 & 7 & 22 \\
\hline 7 & 37 & 15.54 & 3.827 & .629 & 14.26 & 16.82 & 7 & 23 \\
\hline 8 & 37 & 13.59 & 3.678 & .605 & 12.37 & 14.82 & 6 & 20 \\
\hline 9 & 37 & 13.97 & 3.862 & .635 & 12.69 & 15.26 & 6 & 21 \\
\hline 10 & 37 & 14.14 & 3.735 & .614 & 12.89 & 15.38 & 6 & 22 \\
\hline 11 & 37 & 13.30 & 3.950 & .649 & 11.98 & 14.61 & 6 & 22 \\
\hline 12 & 37 & 17.41 & 4.561 & .750 & 15.88 & 18.93 & 6 & 24 \\
\hline Total & 444 & 14.27 & 3.881 & .184 & 13.90 & 14.63 & 6 & 24 \\
\hline
\end{tabular}

According to Table 8 , six posters were evaluated by respondents $(\mathrm{N}=37)$ using the 12 items health message review tool at $95 \%$ level of significance. The highest mean with a standard deviation is shown by poster 3 $(M=33.84, S D=10.348)$. Conversely, poster 6 holds the lowest average score with a minimum standard deviation $(M=21.54, S D=7.866)$. The average scores of other posters i.e. poster $1(M=26.92, S D=8.084), 2(M=27.81$, $S D=7.397), 4(\mathrm{M}=25.78, S D=9.013)$ and $5(\mathrm{M}=26.11, S D=8.993)$ were almost the same. 
Table 9. Leven's test analysis of homogeneity of dengue campaign posters

\begin{tabular}{lccc}
\hline Levene Statistic & $\mathrm{df1}$ & $\mathrm{df} 2$ & Sig. \\
\hline 1.334 & 5 & 216 & .251 \\
\hline
\end{tabular}

According to Table 9, Levene's test of homogeneity of variance shows a $\mathrm{P}$ value of 0.251 ( $\mathrm{P}>0.05)$. It means that the posters' variances are equal. In other words, the posters are homogenous.

Table 10. ANOVA test shows statistically different posters among all six dengue campaign posters

\begin{tabular}{lccccc}
\hline & Sum of Squares & df & Mean Square & F & Sig. \\
\hline Between Groups & 2941.514 & 5 & 588.303 & 7.824 & .000 \\
Within Groups & 16240.486 & 216 & 75.187 & & \\
Total & 19182.000 & 221 & & & \\
\hline
\end{tabular}

As seen from Table 10, the F value for a one-way ANOVA test is $7.824(\mathrm{P}=0.000$ at the $95 \%$ level of significance). Since the P-value is less than 0.05 , the null hypothesis is rejected. Based on these results, it can be concluded that at least one poster is significantly statistically different from the others. Therefore, a post hoc Tukey test is run to follow up where the differences exactly are.

Table 11. The most and the least persuasive poster based on Tukey HSD test results

\begin{tabular}{|c|c|c|c|c|c|}
\hline & \multirow{2}{*}{ Type of Poster } & \multirow{2}{*}{$\mathrm{N}$} & \multicolumn{3}{|c|}{ Subset for alpha $=0.05$} \\
\hline & & & 1 & 2 & 3 \\
\hline \multirow{7}{*}{ Student-Newman-Keuls ${ }^{\mathrm{a}}$} & Poster 6 & 37 & 21.54 & & \\
\hline & Poster 4 & 37 & 25.78 & 25.78 & \\
\hline & Poster 5 & 37 & 26.11 & 26.11 & \\
\hline & Poster 1 & 37 & & 26.92 & \\
\hline & Poster 2 & 37 & & 27.81 & \\
\hline & Poster 3 & 37 & & & 33.84 \\
\hline & Sig. & & .063 & .746 & 1.000 \\
\hline \multirow{7}{*}{ Tukey HSD ${ }^{a}$} & Poster 6 & 37 & 21.54 & & \\
\hline & Poster 4 & 37 & 25.78 & 25.78 & \\
\hline & Poster 5 & 37 & 26.11 & 26.11 & \\
\hline & Poster 1 & 37 & 26.92 & 26.92 & \\
\hline & Poster 2 & 37 & & 27.81 & \\
\hline & Poster 3 & 37 & & & 33.84 \\
\hline & Sig. & & .086 & .916 & 1.000 \\
\hline
\end{tabular}

Note. Means for groups in homogeneous subsets are displayed; a. Uses Harmonic Mean Sample Size = 37.000.

Table 11 shows that poster $1,4,5$, and 6 are significantly different from poster 2 and 3 . Poster 2 is significantly different from poster 1, 4, 5, 6 and poster 3 . From these findings, it can be concluded that poster 3 is significantly different and achieved the most score for least persuasive (score 33.84, p<0.000)) and poster 6 is the most persuasive (score 21.54) one.

\section{Discussion}

This study focused on the writing, identification of key message elements and evaluation of dengue posters with recommendation for improvement. The results of the qualitative data analysis revealed that the health campaign materials writing sessions can be more successfully carried out when participants' have identified various elements i.e. word patterns, concepts and relationship between concept pairs (see Table1 to Table 6) in their first session on handwritten poster making. The second session significantly enhanced the students' knowledge on designing posters. In the second session, students were encouraged to use persuasive technology (computer, handphone, graphic variables) to design posters more effectively and persuasively so that the weaknesses based on observation and evaluation of hand-written posters can be overcome. Other campaign materials, e.g. pamphlets, brochures, billboards may well be constructed in the same way in language classrooms. These two classes also 
helped the participants to identify elements of health campaign posters which are inherently complex. This means that when they came to the first class, they were unsure about all the message components: objectives, audience, message, image-text combination, layout, use of fonts, and sizes of the fonts. Evaluation and recommendation for improving the posters have contributed significantly in enhancing their understanding of the strategies being used to make them more effective and convincing. For instance, they were able to make use of the message elements either in drawing or designing the posters. Posters without those elements were recommended for further writing and checked for improvement.

The use of vivid visual and verbal text is the most striking finding of this study. As Kress and van Leeuwen (2006) argues that text alone cannot provide a complete meaning; rather a partial picture of it. The meaning becomes richer and fuller when images are added to the text (University of London, 2012).

One of the major findings is the students' use of theory in developing the posters as theory can finally guide message writers to write the campaign message (Slater, 1999, pp. 186-198; Noar, 2006). However, settling on the message information for changing behaviours is a complex matter since people do not change their beliefs, attitudes towards a message and take suggestive action so easily (McGuire, 1981, pp. 41-70; Manoff, 1985). That is why Snyder (2007) thinks that new information to the target people should be highlighted in order to change their behaviour for making a campaign successful. Considering health beliefs, the knowledge that either support or create barriers to habit change, perceived benefits and risks can go a long way in producing persuasive messages (Andreasen, 1995; Manoff, 1985). Presentation of health messages is equally important for accepting or rejecting them, let alone writing precisely and logically.

Another interesting finding is that the use of graphics enabled the participants to write and produce posters effectively. They used computer and mobile applications freely to write and design dengue posters. Inevitably, these posters appeared to be more attractive and persuasive (see computer-generated posters in Figures 3, 4 \& 5) when compared with hand-drawn ones (hand-drawn posters in Figures 6, $7 \& 8$ ).

Culture is a predominant force since it shapes behaviours, values, and institutions (Arkin, 1992, p. 59). It is crucial to understand and reflect the appropriate culture of the target population before constructing campaign messages, especially if they are written for people representing various races, values, and cultures. One message may be appropriate for one culture but may not be suitable for other cultures. For instance, typical linguistic use of the Malay population has reshaped the language use, i.e. optative verbs are used instead of imperatives (Ambil peduli... vs. Jom...meaning take care vs. let us...). The following dimensions are vital for writing messages for a diverse cultural setting: primary factors that are related to race, ethnicity, language, nationality and religion and secondary factors linking to age, gender, sexual orientation, level of education, occupation, income level, and acculturation to mainstream.

A unique finding of this study is the use of persuasive elements, e.g. popular cartoon characters like Spiderman in Figure 5, Transformer in Figure 6 and imagery to draw the attention of children. These characters are attractive to children. Siddayao (2012) claimed the same in his study on dengue poster evaluation. The use of metaphor in poster 1 Figure 4 also marks the use of rhetoric language (see Table 7). The indented meaning of the metaphor may not be comprehended by the target audience (Phillips, 1997 as cited in Morgan \& Reichert, 1999). For instance, the comparison between dengue and Mercedes is made to indicate speedy suffering of the patient i.e. dengue patient can quickly die if not treated well.

The major quantitative findings present the descriptive mean analysis showing the highest, lowest and almost the same mean scores of the selected posters (see Table 8). The ANOVA test, on the other hand, suggests that all six dengue posters were homogeneous and significantly different. However, poster six was the most persuasive one while poster 3 turned out to be the least persuasive one.

We have identified a few limitations in this study. This study only focused on a small number of dengue posters due to the set-up of action research. So, the finding cannot be representative or generalized. Another limitation is this investigation has not considered the current media habits of the target audience. There are popular media like Facebook, Twitter, and so on that may play a crucial role in disseminating dengue messages. Knowing the media habits of the target population will help message producers develop messages that can be circulated via different media/medium (Snyder, 2007). For example, a campaign targeting the mass population by sending messages on the Internet may not be accessed by the same number of the populace.

Language use plays an integral part in writing and designing health campaign materials. Therefore, the placement of language or languages (in the case of multi-cultural and a multi-linguistic target audience) can be a crucial issue (Ma, 2005). The ratio of using more than one language in designing the posters or other materials to entice and persuade the intended audience either to create awareness or change current unhealthy habits may equally be an 
essential aspect of any investigation. This study did not cover that. Future researchers may be interested in that area.

However, this study indeed provides some shreds of evidence to inform health or government agencies about persuasive health campaign poster writing strategies by looking at how the posters are evaluated and using the recommendations to improve for the intended audience. The knowledge and the outcomes of the practice sessions may be used in health education classes by developing a module. Janson (2003) claims that even though health promotion campaigns in the mass media have tried their best to persuade the target population to adopt healthy behaviours through messages, yet they may fail in achieving the desired attention from the media due to boring, irrelevant and difficult to understand messaging. The results may also provide some ideas for present researchers on module development of health campaign messages and the systematic approach of designing posters. They can use graphic variables along with conventional texts to plan, arrange materials to produce posters that may cause misinterpretation resulting from the complex use of visual messages (M. Borba, Wachter, \& V. Borba, 2015).

\section{Acknowledgements}

Special thanks to the students who participated by writing, presenting and evaluating the posters in this action research, and to the lecturers who invited the researchers to conduct session on health campaign messages. We would also like to thank all who made valuable comments for the improvement of this publication. The authors gratefully acknowledge the Research Management Center, Universiti Putra Malaysia for funding this research (GP-IPS/2018/9665000).

\section{References}

Andreasen, A. (1995). Marketing social change: Changing behaviour to promote health, social development, and the environment. San Francisco, Calif: Jossey-Bass.

Arkin, E. B. (1992). Making health communication programs work: A planners guide. Diane Publishing.

Atkin, C. K., \& Rice, R. E. (2012). Advances in public communication campaigns. The international encyclopedia of media studies. https://doi.org/10.1002/9781444361506.wbiems129

Avila, G. M., Martinez, M., Sherman, C., \& Fernández, E. C. (2004). Evaluation of an educational module on dengue and Aedes aegypti for schoolchildren in Honduras. Revista panamericana de salud publica (Pan American journal of public health), 16(2), 84-94. https://doi.org/10.1590/S1020-49892004000800003

Bates, M. E. (2014). Fear as a motivator in health campaigns: An examination of fear appeals messaging and skin cancer prevention (Doctoral dissertation, Clemson University).

Borba, M. R., Waechter, H. N., \& Borba, V. R. (2015). Contributions of Graphic Design for Effective Communication in the Health Campaigns. Blucher Design Proceedings, 2(2), 82-90. https://doi.org/10.5151/designpro-CIDI2015-cidi_86

Bradbury, H., \& Reason, P. (2006). Conclusion: Broadening the bandwidth of validity: Issues and choice-points for improving the quality of action research. Handbook of action research, 343-351.

Brookes, G., \& Harvey, K. (2015). Peddling a semiotics of fear: a critical examination of scare tactics and commercial strategies in public health promotion. Social Semiotics, 25(1), 57-80. https://doi.org/10.1080/10350330.2014.988920

Coffman, J. (2003). Lessons in evaluating communications campaigns: Five case studies. Harvard Family Research Project. Retrieved from http://www.mediaevaluationproject.org/HFRP2.pdf

Evans, W. D., Uhrig, J., Davis, K., \& McCormack, L. (2009). Efficacy methods to evaluate health communication and marketing campaigns. Journal of health communication, 14(4), 315-330. https://doi.org/10.1080/10810730902872234

Frank, L. B., Murphy, S. T., Chatterjee, J. S., Moran, M. B., \& Baezconde-Garbanati, L. (2015). Telling stories, saving lives: creating narrative health messages. Health communication, 30(2), 154-163. https://doi.org/10.1080/10410236.2014.974126

Head, K. J., Noar, S. M., Iannarino, N. T., \& Harrington, N. G. (2013). Efficacy of text messaging-based interventions for health promotion: a meta-analysis. Social science \& medicine, 97, 41-48. https://doi.org/10.1016/j.socscimed.2013.08.003

Hong, Y. H., Soh, C. H., Khan, N., Abdullah, M. M. B., \& Teh, B. H. (2013). Effectiveness of anti-smoking advertising: the roles of message and media. International Journal of Business and Management, 8(19), 55. 
https://doi.org/10.5539/ijbm.v8n19p55

Jansen, C. (2003). Developing persuasive health campaign messages. The Gower Handbook of Information Design (pp. 1-17).

Kress, G. R., \& Van Leeuwen, T. (1996). Reading images: The grammar of visual design. Psychology Press.

Ma, M. L. (2005). Multimodal discourse analysis of advertisements of Hong Kong charity organizations (Thesis). University of Hong Kong, Pokfulam, Hong Kong SAR.

Manoff, R. (1985). Social marketing. New York: Praeger.

McGuire, W. (1981). The theoretical foundation of campaigns.

McGuire, W. (1981). The theoretical foundation of campaigns. In R. E. Rice, \& W. J. Paisley (Eds.), Public Communication Campaigns (pp. 41-70). Beverly Hills, Calif: Sage.

McGuire, W. (2001). Input and Output variables currently promising for constructive persuasive communications. In R. Rice, \& C. Atkin (Eds.), Public communication campaigns (pp. 22-48). SAGE publications: California. https://doi.org/10.4135/9781452233260.n2

Mindanao Training Resource Centre. (n.d.). A training manual on development communication. Davao City.

Morgan, S. E., \& Reichert, T. (1999). The message is in the metaphor: Assessing the comprehension of metaphors in advertisements. Journal of Advertising, 28(4), 1-12. https://doi.org/10.1080/00913367.1999.10673592

Morrison, F. P., Kukafka, R., \& Johnson, S. B. (2005). Analyzing the structure and content of public health messages. In AMIA Annual Symposium Proceedings (Vol. 2005, p. 540). American Medical Informatics Association.

Nabi, R. L. (2003). Exploring the framing effects of emotion: Do discrete emotions differentially influence information accessibility, information seeking, and policy preference? Communication Research, 30(2), 224-247. https://doi.org/10.1177/0093650202250881

National Cancer Institute. (1992). Making health communication programs work: A planner's guide [Electronic version]. Washington, DC: Author.

Noar, S. M. (2006). A 10-year retrospective of research in health mass media campaigns: Where do we go from here? Journal of health communication, 11(1), 21-42. https://doi.org/10.1080/10810730500461059

Phillips, B. J. (1997). Thinking into it: Consumer interpretation of complex advertising images. Journal of Advertising, 26(2), 77-87. https://doi.org/10.1080/00913367.1997.10673524

Poovaneswari, S. (1993). Dengue situation in Malaysia. Malaysian Journal of Pathology, 15(1), 3-7.

Popesku, L., \& Verman, D. (2000). Strategies for Developing a Health Promotion Campaign. Common Health (pp. 24-25).

Public Health Ontario. (2012). Health communication message review criteria (2nd ed.). Toronto, ON: Queen's Printer for Ontario.

Rice, R. E., \& Atkin, C. K. (eds.), (2001). Public Communication Campaigns. Sage Publications: Thousand Oaks, CA.

Rosli, H., \& Rahim, R. A. (2015). Preventing Childhood Obesity Through Poster Design. In International Colloquium of Art and Design Education Research (i-CADER 2014) (pp. 621-629). Springer, Singapore. https://doi.org/10.1007/978-981-287-332-3_64

Rozhan, S., Jamsiah, M., Rahimah, A., \& Ang, K. T. (2006). The COMBI (Communication for Behavioural Impact) program in the prevention and control of Dengue-The Hulu Langat experience. Jurnal Kesihatan Masyarakat (Malaysia), 12(1), 1-13.

Savage, M. W., Scott, A. M., Aalboe, J. A., Stein, P. S., \& Mullins, R. (2015). Perceptions of oral health in Appalachian Kentucky: Implications for message design. Health communication, 30(2), 186-195. https://doi.org/10.1080/10410236.2014.974127

Shimp, T. (2000). Advertising, promotion, and supplemented aspects of integrated marketing communications (6th ed.). Orlando, FI: Harcourt. https://doi.org/10.1207/S15327027HC1104_2

Shoemaker, P. J., \& Reese, S. D. (1996). Mediating the message (pp. 781-795). White Plains, NY: Longman. 
Siddayao, J. Y. (2012). Evaluation of anti-dengue campaign posters in Irisan, Baguio City (Unpublished Bachelor of Science thesis). Benguet State University, La Trinidad, Benguet.

Slater, M. D. (1999). Integrating application of media effects, persuasion, and behavior change theories to communication campaigns: A stages-of-change framework. Health Communication, 11(4), 335-354. https://doi.org/10.1207/S15327027HC1104_2

Smith, M. K. (2001). 'Action research', the encyclopedia of informal education. Retrieved from http://infed.org/mobi/action-research/

Snyder, L. B. (2007). Health communication campaigns and their impact on behavior. Journal of Nutrition Education and Behavior, 39(2), S32-S40. https://doi.org/10.1016/j.jneb.2006.09.004

Stephenson, M. T., \& Witte, K. (2001). Generating fear in a risky world: Creating effective risk messages. In R. E. Rice, \& C. K. Atkin (Eds.), Public communication campaigns (3rd ed.). Thousand Oaks, CA: Sage.

Sutton, J., Spiro, E. S., Johnson, B., Fitzhugh, S., Gibson, B., \& Butts, C. T. (2014). Warning tweets: Serial transmission of messages during the warning phase of a disaster event. Information, Communication \& Society, 17(6), 765-787. https://doi.org/10.1080/1369118X.2013.862561

Tigalo, T. V., \& Keyes, A. L. (1958). A guide for health education of the public (pp. 39-58). Institute of Hygiene, University of the Phillippines.

University of London (Producer). (Mar 15, 2012). What is mode? [Video file]. Retrieved from https://www.youtube.com/watch?v=kJ2gz_OQHhI

Valbuena, V. T. (1987). Public health education campaigns in Singapore. In AMIC Workshop on Social Marketing and Public Education Campaigns: Baguio, May 18-26, 1987. Singapore: Asian Mass Communication Research and Information Centre.

Vanderpool, R. C., Cohen, E. L., Crosby, R. A., Jones, M. G., Bates, W., Casey, B. R., \& Collins, T. (2013). "1-2-3 Pap" intervention improves HPV vaccine series completion among Appalachian women. Journal of Communication, 63(1), 95-115. https://doi.org/10.1111/jcom.12001

World Health Organization. (2017). Vector-borne diseases. Retrieved from https://www.who.int/news-room/fact-sheets/detail/vector-borne-diseases

Yzer, M., LoRusso, S., \& Nagler, R. H. (2015). On the conceptual ambiguity surrounding perceived message effectiveness. Health communication, 30(2), 125-134. https://doi.org/10.1080/10410236.2014.974131

Zhao, X., \& Peterson, E. (2017). Effects of temporal framing on response to antismoking messages: The mediating role of perceived relevance. Journal of health communication, 22(1), 37-44. https://doi.org/10.1080/10810730.2016.1250844

\section{Appendix A}

Health Message Review Tool

Review Criteria
The message will get and maintain the attention of the audience.
The strongest points are given at the beginning of the message.
The message is clear.
The action you are asking the audience to take is reasonably easy.
The message uses incentives effectively.
Good evidence for threats and benefits is provided.
The messenger is seen as a credible source of information.
Messages are believable.
The message uses an appropriate tone for the audience.
The message uses an appeal that is appropriate for the audience.
The message will not harm or be offensive to people who see it.
Identity is displayed throughout.

Final recommendation: Use $\square$ Lose $\square$ Adapt $\square$

Adapted (Source: Public Health Ontario, 2012) 


\section{Appendix B}

The classroom activities with set learning objectives and achieved outcomes with final remarks on any activity or response of the participants

\begin{tabular}{|c|c|c|c|}
\hline No. & Activity in the classroom & Learning Objectives & Learning outcomes \\
\hline 1 & Warm-up activity & Rapport build-up & warm-up \\
\hline 2 & $\begin{array}{l}\text { Checking their current level of knowledge } \\
\text { (follow-up questions) on health campaigns }\end{array}$ & $\begin{array}{l}\text { To see the difference between current and } \\
\text { new knowledge }\end{array}$ & $\begin{array}{l}\text { Be able to share their current level } \\
\text { of knowledge }\end{array}$ \\
\hline 3 & $\begin{array}{l}\text { Sharing new knowledge (Using PPT and Video) } \\
\text { on the same to prepare and guide them to write } \\
\text { campaign posters }\end{array}$ & $\begin{array}{l}\text { To be able to learn new additional } \\
\text { knowledge based on the TA's needs }\end{array}$ & $\begin{array}{l}\text { Be able to learn them reflected } \\
\text { them in posters writing later }\end{array}$ \\
\hline 4 & $\begin{array}{l}\text { Putting them in poster-making session with } \\
\text { objectives }\end{array}$ & 3 Clear objectives were set for each session & Be able to achieve them \\
\hline 5 & Monitoring them while writing posters & $\begin{array}{l}\text { To stop free riders to ensure everybody's } \\
\text { performance; weaker participants were } \\
\text { assisted to the task }\end{array}$ & $\begin{array}{l}\text { Be able to respond to the task and } \\
\text { facilitation }\end{array}$ \\
\hline 6 & Participants presenting posters to the class & $\begin{array}{l}\text { To taste a sense of achievement and be } \\
\text { competitive }\end{array}$ & $\begin{array}{l}\text { Be able to be motivated, } \\
\text { enthusiastic and feel proud of their } \\
\text { achievements }\end{array}$ \\
\hline 7 & Evaluating the produced posters using checklist & To check and rank the posters & $\begin{array}{l}\text { Be able to grade posters based on } \\
\text { the checklist }\end{array}$ \\
\hline 8 & Closing the sessions & To learn to be time-bound and productive & Be able to act accordingly \\
\hline
\end{tabular}

\section{Copyrights}

Copyright for this article is retained by the author(s), with first publication rights granted to the journal.

This is an open-access article distributed under the terms and conditions of the Creative Commons Attribution license (http://creativecommons.org/licenses/by/4.0/). 